\title{
Can socio-economic differences explain low expectation of health services among HIV patients compared to non-HIV counterparts?
}

Jing $\mathrm{Li}^{1,2}$, Sawitri Assanangkornchai ${ }^{i^{*}}$, Lin Lư ${ }^{3}$, Le Cai ${ }^{2}$, Jing You ${ }^{4}$, Edward B. McNeil ${ }^{1}$ and Virasakdi Chongsuvivatwong ${ }^{1}$

\begin{abstract}
Background: The health service of China has encountered significant challenges due to inequalities in socioeconomic determinants of health. HIV patients are known to suffer from social stigma, and may receive inadequate responsiveness from health providers. Before assessing the responsiveness they receive, it is important to know their expectations. We aimed to compare levels of expectation towards the healthcare service among HIV and non-HIV patients with adjustment for socio-economic factors.

Methods: A cross-sectional study was conducted during January and February, 2015 among two consecutive groups of HIV positive and non-HIV patients in two hospitals in Kunming, China. Patients' expectation towards eight domains of health system responsiveness was measured using 40 vignettes; five per domain. Each vignette was ranked from 1 "very good" to 5 "very bad", and the responses were summed to obtain a total score for each domain. Differences in total scores were compared between the two groups and adjusted for other factors using multiple linear regression.

Results: The three domains with the highest scores, reflecting high expectation, were prompt attention, basic amenities and choice. Adjusted for other factors, HIV patients had significantly lower levels of expectation in all domains compared to the non-HIV group. Age was associated with the basic amenities domain, with young adults having higher expectations than other age groups. Minority ethnic groups had lower expectation towards dignity, prompt attention and autonomy domains compared to Han ethnicity. Those who lived in a home with 2-4 family members had higher expectations towards confidentiality than those who lived alone.

Conclusion: Patients with HIV have significantly lower levels of expectations even after adjusting for socio-economic factors. Assessment of health system responsiveness based on their judgments above may give biased results toward favorable service quality.
\end{abstract}

Keywords: Expectation, HIV patients, Socio-economic factors, Health system, China

* Correspondence: savitree.a@psu.ac.th

${ }^{1}$ Epidemiology Unit, Faculty of Medicine, Prince of Songkla University, Hat

Yai, Songkhla 90110, Thailand

Full list of author information is available at the end of the article 


\section{Background}

Patient expectations prior to seeking healthcare services and their perceptions of the care after consuming the service positively affect their satisfaction of the service and confirm or refute their re-visits of the service $[1,2]$. Expectations of healthcare systems are proportional to their attractiveness. Patient's expectations of medical care are linked to the cost of treatment [3], assessments and satisfaction $[4,5]$. When the perception of patients towards healthcare meets the expectation of patients [6], a healthcare system will arrive at the perfect level, which appeals to patient-centered medical services [7]. However, there has been little research on the expectation of patients with human immunodeficiency virus infection and acquired immune deficiency syndrome (HIV/AIDS) in comparison to other patients. With the rapid economic development in China, equity of health services faces significant challenges due to a vicious cycle of factors such as inequalities of socio-economic determinants of health $[8,9]$ and growing dissatisfaction about health system fairness $[10,11]$ among the public. The high prevalence of HIV/AIDS [12], broad utilization of antiretroviral therapy (ART) and inadequate access to health services $[13,14]$ combine to create parallel challenges of the HV/AIDS healthcare system. Health systems of China are facing reforms with aims to expand access to more healthcare services and enhance the quality in terms of non-clinical aspects in order to meet the people's new expectations [15].

According to the WHO framework for assessing the performance of health systems [6], patients' expectations of healthcare services are categorized into eight domains of health system responsiveness: dignity, confidentiality, communication, autonomy, prompt attention, quality of basic amenities, social support and choice of provider [16]. These domains are related to patient rights, and reflect their expectation of healthcare services according to their perception of healthcare.

In the measurement of expectation, bias due to reporting heterogeneity among survey respondents from different groups with different preferences and cultural norms make cross-cultural comparison of ordinal response categories invalid. A clinical vignette is a short and clear scenario presenting a hypothetical clinical situation, and can resolve this "response-category differential item functioning" [17]. The response of patients to each scenario thereby reveals their perceptions, values, social norms or impressions of clinical events. Such vignettes have been used to assess opinions or preferences across countries, healthcare systems, and specialties [18, 19]. As a marginalized population, HIV/AIDS patients are more vulnerable in healthcare compared to other patients due to the heavy HIV/AIDS stigma and discrimination. However, there is no study focusing on their expectations compared to their counterparts in healthcare setting especially based on vignettes.

Patients' expectations are affected not only by age [20, 21 and sex, but also by occupation [22, 23], education [23], and income-conventional indicators of socioeconomic status (SES). Although different socio-economic indicators have comparable effects on patients' expectations, a convincing causal relationship between SES indicators and patients' expectation towards quality of HIV/ AIDS healthcare remains to be established.

The presence of socio-economic disparities among HIV patients compared to their non-HIV counterparts may be damaging not only from a human rights perspective but also in sustaining confidence in the system. Identifying the extent of such socio-economic disparities can be the first step in improving the quality of health services and patient satisfaction with services within HIV/AIDS health systems. In this current paper, we aimed to compare levels of expectation of HIV and nonHIV patients in eight domains separately adjusted for different socio-economic factors. The results could be useful for the ongoing healthcare reform process in order to improve the quality of HIV/AIDS care.

\section{Methods}

\section{Study setting and design}

A cross-sectional study was conducted from $1^{\text {st }}$ January 2015 to $15^{\text {th }}$ February 2015 . The study was conducted in the infectious departments of two large hospitals: a special infectious hospital and a general hospital in Kunming, the capital city of Yunnan Province, China. The two hospitals have the largest numbers of HIV patients in Kunming. In these hospitals, both HIV/AIDS and non-HIV patients visit the infectious departments. The majority of non-HIV patients have viral hepatitis or other infectious diseases without tuberculosis. All HIV and non-HIV in- and out-patients aged 15 years old or more attending the infectious department of the two study hospitals were eligible to join the study. Patients with tuberculosis were excluded because tuberculosis is one of the most common opportunistic infections of HIV patients. Those who could not communicate in Chinese or were too ill to be interviewed were also excluded. Consecutive sampling was used to recruit study subjects.

\section{Sample size}

Sample size estimation was based on the formula for comparing two population means. We used the confidentiality score to calculate the sample size using the smallest difference between the two groups in a pilot study resulting in the largest sample size. The mean scores (SD) for confidentiality among HIV and non-HIV were 16.77 (3.29) and 17.21 (2.13). With these parameters, the number of subjects 
required to detect a difference in mean confidentiality scores between two groups, with type one probability of 0.05 and $80 \%$ power, would be 624 per group. To compensate for an estimated $10 \%$ incomplete response rate, 694 were required in each group.

\section{Development and modification of vignettes}

The vignettes were developed by using a standardized protocol from the World Health Survey (WHS) responsiveness module (short version). We firstly selected vignettes for health system responsiveness of Set A to Set $\mathrm{D}$ involved in eight domains. Vignettes of Set A focus on two domains: respectful treatment (dignity) and prompt attention, Set B: clear communication and quality of basic amenities, Set C: confidentiality and choice of care provider, and Set D: social support to patient and autonomy. Each set includes ten vignettes, five for each domain. Each vignette simulates patient visits and healthcare provider's responsiveness to the patient in the relative domain. In each set, ten vignettes of the two domains were mixed in random order.

The vignettes were translated into Chinese and modified by the main researcher to suit the Chinese context. A team of healthcare experts including two chief physicians of infectious departments of the two hospitals, and an expert of HIV/AIDS prevention in the Centre for Disease Control of Yunnan Province, reviewed and finalized the Chinese version of the vignettes. The finalized version was back translated into English and compared with the original version in order to establish the validity of the Chinese version. A focus group discussion consisting of ten non-HIV patients was assembled, and indepth interviews were conducted with five HIV patients to obtain cultural and contextual relevance. The respondents were asked specific questions in order to determine whether questions were understandable and whether the intent of each question was accurately conveyed. They were also asked to elaborate on the reasons why a particular response category was chosen for a question. According to their suggestions, we modified the vignettes for clearer comprehensibility and cultural suitability. In December of 2014, a pilot study was conducted among 45 HIV and non-HIV patients in both hospitals. It took 60 to $70 \mathrm{~min}$ for a patient to complete the questionnaire. The instrument was then shortened to 40 to 60 min duration.

A sample of five vignettes on the dignity domain was as follows:

- [Xiao Zhang] was pregnant and went to the hospital coughing blood. A nurse welcomed her gently and helped her to a private room. A female doctor came to examine her and gave her a clean gown to replace her blood-stained clothes.
- $[$ Xiao Qu] had bad flu. He went to the clinic. The nurse expressed concern about [Xiao Qu]'s cough and called the doctor, who gave [Xiao $\mathrm{Qu}]$ a full chest examination behind a large screen that hid him from the view of other patients.

- [Xiao Ting] went to a crowded clinic. At first, no-one greeted her but after waiting for $5 \mathrm{~min}$ a nurse called her to the examination area where she was examined behind a small screen that mostly hid her from the other patients.

- [Wang Li] took her baby for a vaccination. The nurse said hello and but did not ask for [Wang Li's] or the baby's name. The nurse also examined [Wang Li] and made her remove her shirt in the waiting room.

- [Luo Ping] has AIDS. When he goes to his health center the nurses do not talk to him and deliberately ignore him. During examinations, his clothes are removed and he is made to wait, half-naked in the waiting room.

All vignettes for the dignity domain were followed by the question: "How would you rate his/her experience of being greeted and talked to respectfully?" The participants were then instructed to answer this question using a Likert rating scale ranging from 1 representing "very good" to 5 representing "very bad" and 3 representing "moderate". Similar questions were asked for each domain with the same rating scale used to obtain participant's responses.

\section{Study variables and measures}

Dependent variables were the total scores of the eight domains as measured by five vignettes per domain. All five responses were summed to obtain a total score for each domain, with a possible range of 5 to 25 , where higher scores indicate higher expectation towards that domain. Demographic variables, measured by a selfreported questionnaire, included age, gender, ethnicity, religion, place of residence, marital status, family size, education, occupation, and household income. For comparability with other studies, age was arbitrarily grouped into three categories: (i) 40 years old or less (young adults); (ii) 41 to 60 years old (middle-aged); (iii) more than 60 years old (elderly). The nine ethnic groups were classified into two categories: Han and other ethnicity. Place of residence was classified as either rural or urban based on their insurance type. Family size was grouped into 3 categories: (i) single; (ii) 2-4; (iii) 5 or more family members. SES factors included education, occupation, and household income per month. Education was grouped into four levels: (i) primary school or less; (ii) junior high school; (iii) senior high school, and (iv) university or more. Occupation was grouped into four 
Table 1 Distribution of socio-demographic variables

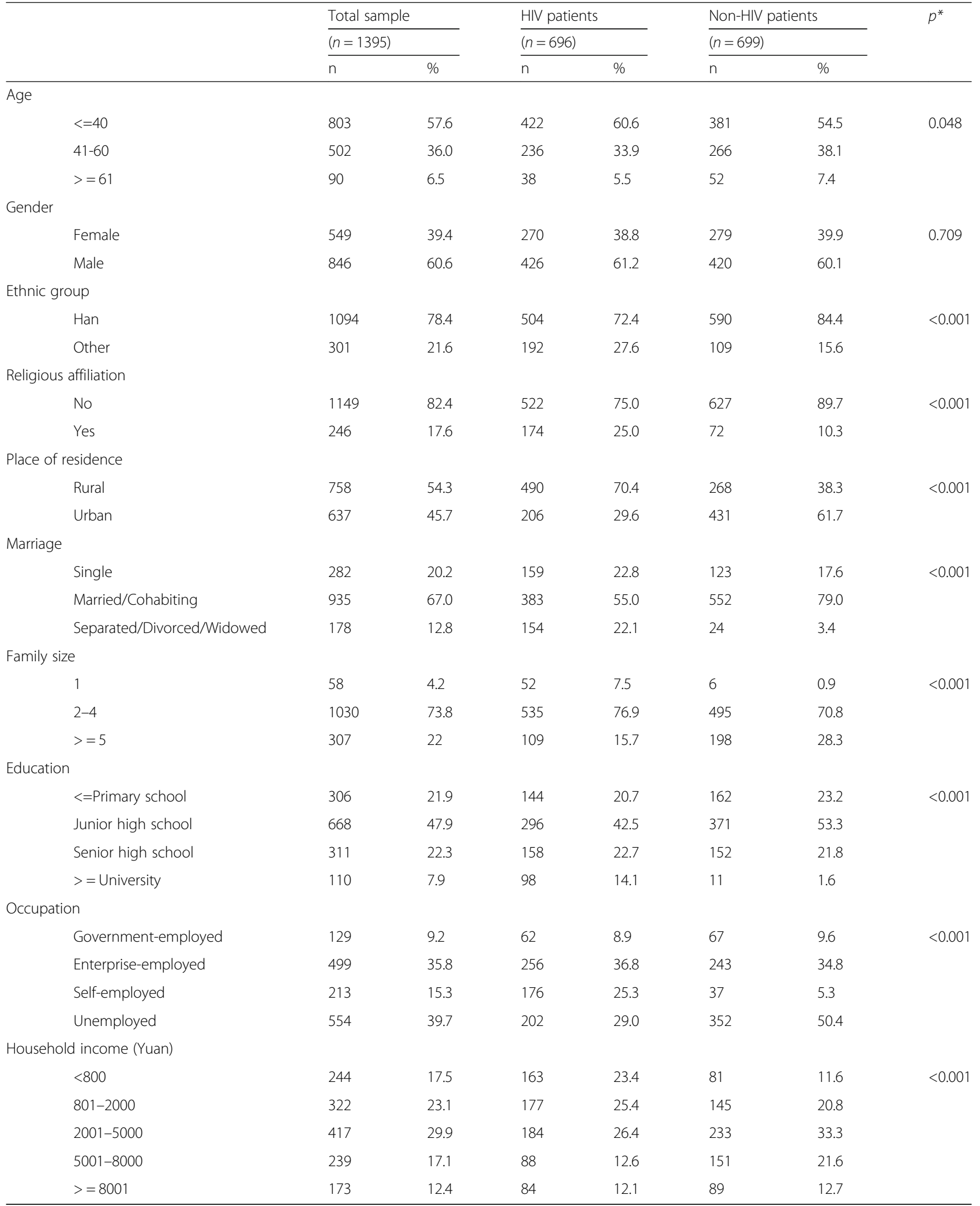

*: All $p$ values in the column were from Chi-squared tests 
categories: (i) government-employed; (ii) enterpriseemployed; (iii) self-employed; (iv) unemployed. Household income was categorized into five levels according to distribution of household income by place of residence in China: (i) 800RMB or less; (ii) $801 \sim 2000 \mathrm{RMB}$; (iii) $2001 \sim 5000 \mathrm{RMB} ; \quad$ (iv) $5001 \sim 8000 \mathrm{RMB}$; 8001RMB or more.

\section{Data analysis}

Comparison of sample characteristics between HIV positive and non-HIV patients was performed using Chisquare goodness-of-fit tests for categorical variables, and $\mathrm{t}$-tests for continuous variables. Comparisons of mean scores for the eight domains were done using t-tests or analysis of variance (ANOVA) as appropriate. Multiple linear regression models were conducted separately for each domain to assess their independent association with demographic variables and SES factors. Variables having a p-value less than 0.05 were considered as significant. All analyses were performed using $\mathrm{R}$ language and environment.

\section{Results}

Two consecutive groups containing 696 HIV and 699 non-HIV patients were included in the study. The response rate was $87 \%$ and $66 \%$ among HIV and nonHIV patients, respectively.

\section{Demographics and socio-economic status}

Table 1 shows the distribution of demographic and socio-economic variables. The majority of patients were male, of Han ethnicity, married or cohabiting, and employed. Most reported having no religious affiliation. About half achieved a junior high school level of education and had a monthly household income of $5000 \mathrm{RMB}$ or less and living in a family of size 2-4 members. Both groups were closely matched on gender; however, HIV positive patients were more likely to belong to a minority ethnicity, have a religious affiliation, live in rural areas, have a higher education level, be separated, divorced or widowed, have a lower household income, live with fewer family members and be self-employed.

\section{Differences in eight domains between HIV and non-HIV patients}

Table 2 presents mean scores of eight domains of patients' expectation of healthcare between HIV and nonHIV patients, based on the vignettes. Of all domains, HIV patients had significantly lower mean expectation scores than non-HIV patients.

\section{Multivariate analyses}

After adjustment for demographic and socio-economic variables, HIV status remained significantly associated
Table 2 Distributions of patients' expectation scores based on vignettes

\begin{tabular}{|c|c|c|c|c|}
\hline & $\begin{array}{l}\text { Total } \\
(n=1395)\end{array}$ & $\begin{array}{l}\text { HIV patients } \\
(n=696)\end{array}$ & $\begin{array}{l}\text { Non-HIV patients } \\
(n=699)\end{array}$ & $p^{*}$ \\
\hline \multicolumn{5}{|l|}{ Dignity } \\
\hline & $14.0(2.5)$ & $13.9(2.7)$ & $14.2(2.2)$ & 0.024 \\
\hline \multicolumn{5}{|l|}{ Prompt attention } \\
\hline & $15.9(2.8)$ & $14.9(3.0)$ & $17.0(2.2)$ & $<0.001$ \\
\hline \multicolumn{5}{|l|}{ Communication } \\
\hline & $14.4(2.2)$ & $14.1(2.5)$ & $14.6(1.7)$ & $<0.001$ \\
\hline \multicolumn{5}{|l|}{ Basic amenities } \\
\hline & $15.5(2.2)$ & $15.2(2.6)$ & $15.8(1.7)$ & $<0.001$ \\
\hline \multicolumn{5}{|l|}{ Confidentiality } \\
\hline & $17.0(2.7)$ & $16.8(3.3)$ & $17.2(2.0)$ & 0.004 \\
\hline \multicolumn{5}{|l|}{ Choice } \\
\hline & $15.7(2.6)$ & $15.3(3.0)$ & $16.2(2.0)$ & $<0.001$ \\
\hline \multicolumn{5}{|l|}{ Social support } \\
\hline & $14.1(2.2)$ & $13.8(2.5)$ & $14.4(1.9)$ & $<0.001$ \\
\hline \multicolumn{5}{|l|}{ Autonomy } \\
\hline & $14.3(2.2)$ & $14.2(2.6)$ & $14.5(1.8)$ & 0.004 \\
\hline
\end{tabular}

$*: p$ values from independent $t$-test

with lower expectations of all health system domains (Table 3). Age was significantly associated with basic amenities, with young adults having a higher expectation. Compared to Han people, minority ethnic groups had lower expectations towards dignity, prompt attention and autonomy. Those who lived in a family containing 2-4 members had a higher expectation than those who lived alone.

Figure 1 compares the crude and adjusted coefficients from the linear regression models among each domain, reflecting the differences in expectation scores between HIV positive and non-HIV patients. Prompt attention had the highest coefficient reflecting a relatively higher expectation by non-HIV patients. Non-HIV patients also had higher expectations towards basic amenities, choice of provider, confidentiality, communication, autonomy, social support and dignity.

\section{Discussion}

HIV patients had lower expectation scores in all health system domains even after adjustment by demographic and socio-economic factors, reflecting lower expectations of the healthcare system. Compared to non-HIV patients, they were slightly younger, belonged to a minority ethnic group, more religious, more educated, self-employed, more likely to be single or separated and had lower household incomes. Thus, on top of having a lower SES, HIV positive patients in this study were further oppressed by their own HIV status. 
Table 3 Multiple linear regression of patients' expectation based on vignettes among eight domains

\begin{tabular}{|c|c|c|c|c|c|c|c|c|c|c|c|c|c|c|c|c|}
\hline & \multicolumn{2}{|l|}{ Dignity } & \multicolumn{2}{|c|}{ Prompt attention } & \multicolumn{2}{|c|}{ Communication } & \multicolumn{2}{|l|}{ Basic amenities } & \multicolumn{2}{|c|}{ Confidentiality } & \multicolumn{2}{|l|}{ Choice } & \multicolumn{2}{|c|}{ Social support } & \multicolumn{2}{|l|}{ Autonomy } \\
\hline & $\begin{array}{l}\text { Coeff. } \\
(95 \% \mathrm{Cl})\end{array}$ & $p$ & $\begin{array}{l}\text { Coeff. } \\
\text { (95\% Cl) }\end{array}$ & $p$ & $\begin{array}{l}\text { Coeff.(95 \% } \\
\mathrm{Cl})\end{array}$ & p & $\begin{array}{l}\text { Coeff. } \\
(95 \% \text { Cl) }\end{array}$ & $p$ & $\begin{array}{l}\text { Coeff. } \\
(95 \% \text { Cl) }\end{array}$ & $p$ & $\begin{array}{l}\text { Coeff. } \\
(95 \% \mathrm{Cl})\end{array}$ & $p$ & $\begin{array}{l}\text { Coeff. } \\
(95 \% \mathrm{Cl})\end{array}$ & $p$ & $\begin{array}{l}\text { Coeff. } \\
\text { (95 \% Cl) }\end{array}$ & $p$ \\
\hline \multirow{2}{*}{$\begin{array}{l}\text { HIV status: } \\
\text { Non-HIV vs. HIV }\end{array}$} & & 0.027 & & $<0.001$ & & $<0.001$ & & $<0.001$ & & 0.003 & & $<0.001$ & & $<0.001$ & & 0.0046 \\
\hline & $\begin{array}{l}0.252 \\
(-0.009,0.513)\end{array}$ & & $\begin{array}{l}2.106 \\
(1.826,2.386)\end{array}$ & & $\begin{array}{l}0.532 \\
(0.302,0.762)\end{array}$ & & $\begin{array}{l}0.587 \\
(0.354,0.821)\end{array}$ & & $\begin{array}{l}0.397 \\
(0.102,0.692)\end{array}$ & & $\begin{array}{l}0.928 \\
(0.662,1.195)\end{array}$ & & $\begin{array}{l}0.543 \\
(0.308,0.778)\end{array}$ & & $\begin{array}{l}0.288 \\
(0.052,0.524)\end{array}$ & \\
\hline Age: ref. $=16-40$ & & & & & & & & 0.0177 & & & & & & & & \\
\hline $41-60$ & & & & & & & $\begin{array}{l}-0.35 \\
(-0.598,-0.102)\end{array}$ & & & & & & & & & \\
\hline $61-85$ & & & & & & & $\begin{array}{l}-0.29 \\
(-0.78,0.201)\end{array}$ & & & & & & & & & \\
\hline \multirow{2}{*}{$\begin{array}{l}\text { Ethnic group: } \\
\text { other vs. Han }\end{array}$} & & 0.0398 & & 0.0178 & & & & & & & & & & & & 0.0046 \\
\hline & $\begin{array}{l}-0.333 \\
(-0.65,-0.016)\end{array}$ & & $\begin{array}{l}-0.412 \\
(-0.752,-0.071)\end{array}$ & & & & & & & & & & & & $\begin{array}{l}-0.415 \\
(-0.701,-0.128)\end{array}$ & \\
\hline $\begin{array}{l}\text { Family size: } \\
\text { ref. }=1\end{array}$ & & & & & & & & & & 0.0389 & & & & & & \\
\hline $2-4$ & & & & & & & & & $\begin{array}{l}0.912 \\
(0.179,1.644)\end{array}$ & & & & & & & \\
\hline$>=5$ & & & & & & & & & $\begin{array}{l}0.74 \\
(-0.045,1.525)\end{array}$ & & & & & & & \\
\hline
\end{tabular}




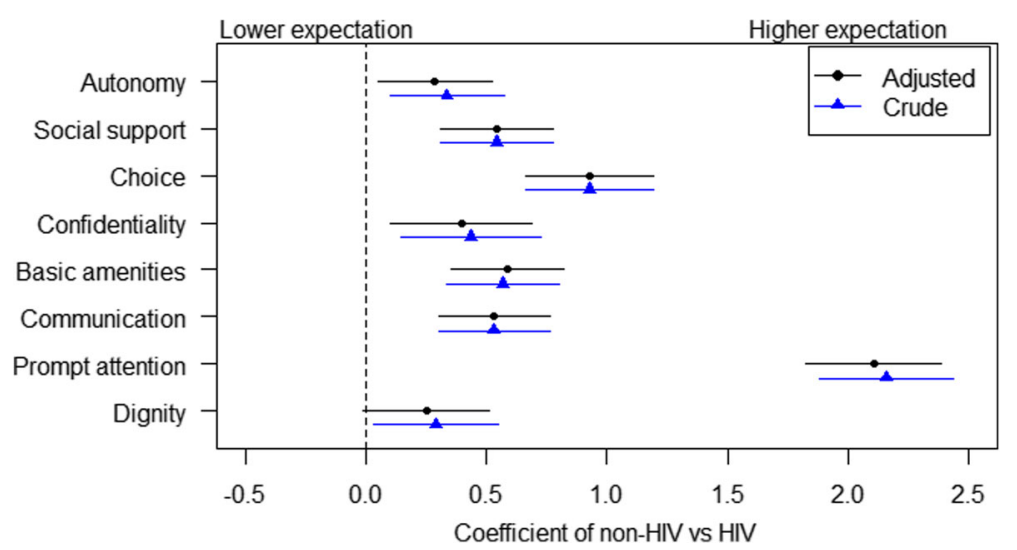

Fig. 1 Differences in health service expectation between HIV and non-HIV patients

Not many studies have focused on differences in expectations of healthcare system between HIV and non-HIV patients across socio-economic status. One study showed that patient's satisfaction with nursing care was associated with younger age, being male, being nonwhite and having HIV [24]. However, that study did not find an independent effect of being HIV positive after adjustment for SES factors.

Among the eight health system domains, prompt attention was found to have the highest difference of expectation between HIV positive and non-HIV patients, and the low expectation of prompt attention by HIV patients suggested that there is a shortage of human resources and a lack of an efficient mechanism to uniformly cooperate in HIV/AIDS care. Additionally, quality of basic amenities is linked to health facilities. One study confirmed that this domain is not strongly correlated with clinical quality, and depends on different hospitals in terms of productivity based on instrumental variables [25]. The lower expectation of HIV patients towards basic amenities reflects their helplessness about dissatisfaction with designated hospitals because of not only limited medical resources but also "logistic choices" to hospitals or providers. Another study considered consulting the same healthcare provider to be a source of comfort in provider-patient relationships. However, the comforting affection from seeing the same provider is on the premise that patients have free choice rights $[26,27]$. The monitoring and evaluation system of China cannot equally share the whole medical resources, and there is a lack of effective operational mechanisms to respond timely to the patient's needs. Under this system, the free choice rights of HIV patents have not been taken into account.

The lower HIV patient expectation in confidentiality can sometimes create a dilemma for health professionals or family members because there is a fine line between safeguarding their privacy and the need to inform other people about their illness. Some studies documented the benefit to patients, especially those with HIV/AIDS, based on humanrights, but others hold the opposite view [28-30]. Besides these, some suggested to identify boundaries of confidentiality [31]. The majority of people living with HIV/AIDS (PLWHA) often avoid naming themselves in public, to their neighbors, and even sometimes to their own family members. As a marginalized population, they are more vulnerable because of the heavy HIV/AIDS stigma [32, 33], especially discrimination by healthcare providers. When disclosing their HIV status, the majority of providers in non-appointed hospitals will refuse to examine and treat them and transfer them to special HIV unit. During their care, there was little dignity [34] given to them because of a lack of effective communication, and lack of prompt attention and respect for individual autonomy [35] such as selfdecisions and meaningful participation. Thus, elimination of stigma is an important goal in the struggle against HIV/ AIDS for subsequent HIV testing and counselling, and adherence to ART. Additionally, confidentiality, choice of provider, dignity and clarity of communication are deserved rights of HIV positive patients. Adopting a human rightsbased approach towards care of HIV/AIDS patients can be very helpful to improve access to HIV prevention, care and treatment.

In terms of social support, HIV patients had a lower expectation compared to their counterparts. Most HIV positive patients expect that they will stay by themselves in hospital, but other patients expect care and contact from their family and friends. The fact that HIV patients abandon their right of access to family and community support may be a consequence of social stigma. Other evidence has shown that decision-making interventions can improve quality of healthcare [36]. This suggests that empowerment of HIV patients within the healthcare system will strengthen quality of healthcare.

Policies in China such as "Four Frees and One Care" has had a great success on expanding the coverage of prevention of mother-to-child transmission and ART. Another 
policy called "HIV/AIDS regulation" first highlighted human rights' protection in early 2006 [37]. However, the effects of empowering these marginalized people in China is lacking. Evidence has shown that empowerment of PLWHA has resulted in policy changes, especially regarding access to free ART. For example, Thailand's response to HIV/AIDS is considered one of the best success stories due to civil society groups as networks at different levels promoted the efficient coordination of activities [38]. Free access to ART has brought massive relief, restoring people's health and enabling them to care for families, providing hope for the future and allowing PLWHA to participate in community activities [39]. In addition, success of Treatment Action Campaign in South Africa, a powerful force in converting donor perceptions of universal access to treatment into a moral imperative, led to policy changes for a global impact in 2004. However, free access to ART cannot replace empowerment of PLWHA in which human rights and fundamental freedoms can be realized.

\section{Limitations}

There are some limitations in our study, which should be acknowledged. Firstly, we could not involve patientsfamily-friends relationships during the decision-making process of seeking healthcare services in our vignette because there are various roles that family or friends play in Chinese culture. Moreover, selection bias was unavoidable since those who did not seek healthcare services or did not know their HIV status were not entered into our study.

\section{Conclusion}

HIV positivity was associated with a lower expectation of the health system, which could not be explained by any socio-economic indicators. Assessment of health system responsiveness based on HIV patient's perception may give biased results toward quality of HIV prevention, care and treatment services, had existing of expectation on care been ignored. In addition, a human rights-based approach to HIV/AIDS patients should be implemented.

\footnotetext{
Acknowledgements

The authors are grateful to staff of Yunnan Center for Disease Prevention and Control: Dr. Manhong Jia for confirmation of fieldwork's feasibility and the Third People's Hospital of Kunming: Dr. YingRong Du for supporting the fieldwork. This study is part of the first author's thesis in partial fulfillment of the requirements for a Ph.D. at Prince of Songkla University, Thailand.
}

\section{Funding}

The study was funded by the China Medical Board through the project titled "Joint Research Capacity Strengthening of the Western Rural Health Network, China" under Prince of Songkla University and a grant from the Graduate School, Prince of Songkla University, Thailand.

The funders had no role in study design, data collection and analysis, decision to publish, or preparation of the manuscript.

\section{Availability of data and materials}

The dataset without personal identification is sharable to interested researchers upon request to Jing $L i$, the first author.

\section{Authors' contributions \\ $J L$ and $S A$ conceived and designed the study with advice from $V C ; \quad J L$ and $V C$ performed the statistical analysis. Each author interpreted the data and contributed to writing the manuscript. All authors read and approved the final manuscript.}

\section{Competing interests}

The authors declare that they have no competing interests.

Consent for publication

Not applicable.

\section{Ethics approval and consent to participate}

The ethical aspects of this study were approved by Prince Songkla University Institutional Review Board and Kunming Medical University. Anonymity of the data was assured and the participants were requested to give their consent to participate in the survey by signing an informed consent form, after providing them with detailed information on the survey procedures.

\section{Author details}

${ }^{1}$ Epidemiology Unit, Faculty of Medicine, Prince of Songkla University, Hat Yai, Songkhla 90110, Thailand. ${ }^{2}$ Kunming Medical University, Kunming, Yunnan Province, China. ${ }^{3}$ Yunnan Center for Disease Prevention and Control, Kunming, Yunnan Province, China. ${ }^{4}$ The First Affiliated Hospital of Kunming Medical University, Kunming, Yunnan Province, China.

Received: 11 March 2016 Accepted: 30 August 2016

Published online: 09 September 2016

\section{References}

1. Staniszewska S, Ahmed L. The concepts of expectation and satisfaction: do they capture the way patients evaluate their care? J Adv Nurs. 1999;29(2):364-72.

2. Lin CS, Wu S, Tsai RJ. Integrating perceived playfulness into expectation-confirmation model for web portal context. Inf Manage. 2005;42(5):683-93.

3. Becker R, Döring C, Denecke A, Brosz M. Expectation, satisfaction and clinical outcome of patients after total knee arthroplasty. Knee Surg Sports Traumatol Arthrosc. 2011;19(9):1433-41.

4. Staniszewska S, Ahmed L. Patient expectations and satisfaction with health care. Nurs Stand. 1998;12(18):34-8.

5. Batbaatar E, Dorjdagva J, Luvsannyam A, Amenta P. Conceptualisation of patient satisfaction: a systematic narrative literature review. Perspect Public Health. 2015;135(5):243-50.

6. Murray CJ, Frenk J. A framework for assessing the performance of health systems. Bull World Health Organ. 2000;78(6):717-31.

7. Rao JK, Weinberger M, Kroenke K. Visit-specific expectations and patientcentered outcomes: a literature review. Arch Fam Med. 2000;9(10):1148.

8 Liu Y, Rao K, Wu J, Gakidou E. China's health system performance. Lancet. 2008;372(9653):1914-23.

9 Chen Z. Launch of the health-care reform plan in China. Lancet. 2009;373(9672):1322-4

10 Tang S, Meng Q, Chen L, Bekedam H, Evans T, Whitehead M. Tackling the challenges to health equity in China. Lancet. 2008;372(9648):1493-501.

11 Yu X, Li C, Shi Y, Yu M. Pharmaceutical supply chain in China: current issues and implications for health system reform. Health Policy. 2010;97(1):8-15.

12 National Health and Family planning Commission of the People's Republic of China: China AIDS response progress report. UNAIDS 2015. Also see: http://www. unaids.org/sites/default/files/country/documents/CHN_narrative_report_2015.pdf. Accessed 15 May 2015

13 Wang L, Wang Y, Jin S, Wu Z, Chin DP, Koplan JP, Wilson ME. Emergence and control of infectious diseases in China. Lancet. 2008:372(9649):1598-605.

14 Zhao R, Chen R, Zhang B, Ma Y, Qin X, Hu Z. Analysis on the development of national HIV/ AIDS monitoring and evaluation system. Zhongguo Ji Bing Kong Zhi Za Zhi. 2012;16:54-6 (in Chinese).

15 Liu Y. Reforming China's health care: for the people, by the people? Lancet. 2009;373(9660):281-3. 
16 WHO. The world health report 2000: health systems: improving performance. World Health Organization 2000.

17 King G, Wand J. Comparing incomparable survey responses: evaluating and selecting anchoring vignettes. Polit Anal. 2007;15(1):46-66.

18 Suh E, Daugherty CK, Wroblewski K, Lee H, Kigin ML, Rasinski KA, Ford JS, Tonorezos ES, Nathan PC, Oeffinger KC. General internists' preferences and knowledge about the care of adult survivors of childhood cancer: a cross-sectional survey. Ann Intern Med. 2014;160(1):11-7.

19 Haider AH, Sexton J, Sriram N, Cooper LA, Efron DT, Swoboda S, Villegas CV, Haut ER, Bonds M, Pronovost PJ. Association of unconscious race and social class bias with vignette-based clinical assessments by medical students. JAMA. 2011;306(9):942-51.

20 Djawe K, Brown EE, Gaul Z, Sutton M. Community-based electronic data collections for HIV prevention research with black/African-American men in the rural, Southern USA. AIDS Care. 2014;26(10):1309-17.

21 Leston JD, Jessen CM, Simons BC. Alaska Native and rural youth views of sexual health: a focus group project on sexually transmitted diseases, HIV AIDS, and unplanned pregnancy. Am Indian Alsk Native Ment Health Res (Online). 2012;19(1):1-14.

22 Krieger N, Barbeau EM, Soobader M-J. Class matters: US versus UK measures of occupational disparities in access to health services and health status in the 2000 US National Health Interview Survey. Int J Health Serv. 2005;35(2):213-36.

23 Rodriguez-Diaz CE, Jovet-Toledo GG, Ortiz-Sanchez EJ, Rodriguez-Santiago El, Vargas-Molina RL. Sexual Health and Socioeconomic-Related Factors Among HIV-Positive Men Who Have Sex with Men in Puerto Rico. Arch Sex Behav. 2015;44(7):1949-58.

24 Webb AA, Bower DA, Gill S. Satisfaction with nursing care: a comparison of patients with HIV/AIDS, non-HIV/AIDS infectious diseases, and medical diagnoses. J Assoc Nurses AIDS Care. 1997;8(2):39-46.

25 Romley JA, Goldman DP. How costly is hospital quality? A revealedpreference approach. J Ind Econ. 2011;59(4):578-608.

26 Anell A, Rosén P, Hjortsberg C. Choice and participation in the health services: a survey of preferences among Swedish residents. Health Policy. 1997:40(2):157-68

27 Beckmann N. Responding to medical crises: AIDS treatment, responsibilisation and the logic of choice. Anthropol Med. 2013;20(2):160-74.

28 Siegler M. Confidentiality in medicine-a decrepit concept. N Engl J Med. 1982:307(24):1518-21.

29 Hemer SR. Breaking silences and upholding confidences: responding to HIV in the Lihir Islands, Papua New Guinea. Med Anthropol. 2015;34(2):124-38.

30 Atuyambe LM, Ssegujja E, Ssali S, Tumwine C, Nekesa N, Nannungi A, Ryan G, Wagner G. HIV/AIDS status disclosure increases support, behavioural change, and HIV prevention in the long term: a case for an Urban Clinic, Kampala, Uganda. BMC Health Serv Res. 2014;14:276.

31 Liamputtong P, Haritavorn N. To tell or not to tell: disclosure to children and family amongst Thai women living with HIV/AIDS. Health Promot Int. 2014:31(1):23-32.

32 Chesney MA, Smith AW. Critical delays in HIV testing and care the potential role of stigma. Am Behav Sci. 1999;42(7):1162-74.

33 Kumar N, Unnikrishnan B, Thapar R, Mithra P, Kulkarni V, Holla R, Bhagawan D, Kumar A. Stigmatization and Discrimination toward People Living with HIV/AIDS in a Coastal City of South India. J Int Assoc Providers AIDS Care. 2015. 2325957415569309

34 Ho AH, Leung PP, Tse DM, Pang SM, Chochinov HM, Neimeyer RA, Chan CL. Dignity amidst liminality: healing within suffering among Chinese terminal cancer patients. Death Stud. 2013;37(10):953-70.

35 Gattellari M, Voigt KJ, Butow PN, Tattersall MH. When the treatment goal is not cure: are cancer patients equipped to make informed decisions? J Clin Oncol. 2002:20(2):503-13.

36 Kimmel AL, Wang J, Scott RK, Briggs L, Lyon ME. FAmily CEntered (FACE) advance care planning: Study design and methods for a patient-centered communication and decision-making intervention for patients with HIV/AIDS and their surrogate decision-makers. Contemp Clin Trials. 2015;43:172-8.

37 Sun X, Lu F, Wu Z, Poundstone K, Zeng G, Xu P, Zhang D, Liu K, Liau A. Evolution of information-driven HIV/AIDS policies in China. Int J Epidemiol. 2010;39 suppl 2:ii4-13.

38 Pongsapich A. Globalization and social development: public-private collaboration for public service delivery. East Reg Organ Public Administration. 2003;4(1-2):55-75.

39 Robins S. 'Long live Zackie, long live': AIDS activism, science and citizenship after apartheid. J South Afr Stud. 2004;30(3):651-72.

\section{Submit your next manuscript to BioMed Central and we will help you at every step:}

- We accept pre-submission inquiries

- Our selector tool helps you to find the most relevant journal

- We provide round the clock customer support

- Convenient online submission

- Thorough peer review

- Inclusion in PubMed and all major indexing services

- Maximum visibility for your research

Submit your manuscript at www.biomedcentral.com/submit
C Biomed Central 